\title{
UM ESTUDO DE CASO SOBRE ADOÇÃO DE UMA CRIANÇA MAIS VELHA
}

\author{
Jéssika Rodrigues Alves \\ Universidade de São Paulo, Ribeirão Preto-SP, Brasil \\ Martha Franco Diniz Hueb \\ Universidade Federal do Triângulo Mineiro, Uberaba-MG, Brasil
}

\begin{abstract}
RESUMO
Este estudo teve como objetivo investigar a representação familiar de uma criança que vivenciou o processo de adoção, a partir do olhar da própria criança, assim como conhecer seu amadurecimento emocional. Participou do estudo um menino de nove anos e sua mãe por adoção. Para a coleta de dados realizou-se uma Entrevista Semiestruturada com a mãe e, com a criança, houve uma Sessão Lúdica, aplicação do Procedimento de Desenhos de Família com Estórias (DF-E) e uma sessão para intervenção sobre os desenhos realizados com a criança. Os dados obtidos foram interpretados segundo método da livre inspeção do material a partir do processo compreensivo, sustentados no referencial winnicottiano. Os resultados evidenciaram a importância de a criança conhecer e possuir abertura para conversar sobre sua história pregressa com seus responsáveis; sendo que, quando há um ambiente acolhedor e o oferecimento de um espaço terapêutico para a criança, que pode ser obtido na família por adoção, isso favorece o amadurecimento emocional. Ademais, destaca-se a necessidade de cuidados da criança que sofreu de-privação e as consequências negativas em se apagar a história do que foi vivido antes da adoção. $O$ estudo remete à importância de as crianças encontrarem na família por adoção um ambiente seguro e acolhedor, que sobreviva aos seus ataques e forneça um espaço em que sua história de vida seja respeitada.
\end{abstract}

Palavras-chave: Família; Adoção; Winnicott.

\section{A CASE STUDY ABOUT OLDER CHILDREN ADOPTION}

\section{AbSTRACT}

This study aimed to investigate the family representation of a child who experienced the adoption process from the child's gaze and evaluate their emotional maturation. A nineyear-old boy and his mother took part in the study by adoption. For the data collection, it was performed a semi-structured interview with the mother and a Play Session. The Family Drawings Procedure with Stories (DF-E) and a session for intervention on the drawings were made with the child. The data obtained was interpreted according to the method of free inspection of the material from the comprehensive process, based on the Winnicottian reference. The results showed the importance of the child knowing and 
having an openness to talk about his/her history with those responsible. In addition, when there is a welcoming environment and the offer of a therapeutic space for the child, available to the family, this allows the emotional maturation of the child. Furthermore, there is a need to care for the child who suffered deprivation, and the negative consequences of erasing the history experienced before the adoption are highlighted. The study points to the children finding in the family by adopting a safe and welcoming environment, surviving their attacks, and providing a space in which their life history is respected.

Keywords: Family; Adoption; Winnicott.

\section{ESTUDIO DE CASO SOBRE LA ADOPCIÓN DE UN NIÑO MAYOR}

\section{RESUMEN}

Este estudio tuvo como objetivo investigar la representación familiar de un niño que vivenció el proceso de adopción, a partir de la mirada del propio niño, y también evaluar su maduración emocional. Participó del estudio un niño de nueve años y su madre por adopción. Para la recolección de datos fue realizada una Entrevista Semiestructurada con la madre y se utilizó una sesión Lúdica, el Procedimiento de Dibujos de Familia con Estorias (DF-E) y de una sesión para intervención sobre los dibujos realizados con el niño. Los datos obtenidos fueron interpretados según el método de la libre inspección del material a partir del proceso comprensivo, sostenidos en el referencial winnicottiano. Los resultados mostraron la importancia de que el niño conozca y tenga apertura para hablar sobre su historia con sus responsables; que, cuando hay un ambiente acogedor y el ofrecimiento de un espacio terapéutico para el niño, que puede obtenerse en la familia por adopción, esto posibilita la maduración emocional. Además, se destaca la necesidad de cuidar al niño que sufrió privación o desprivación y las consecuencias negativas de borrar la historia de lo vivido antes de la adopción. El estudio remite a la importancia de los niños para encontrar en la familia por adopción un ambiente seguro y acogedor que sobreviva a sus ataques y proporcione un espacio en que su historia de vida sea respetada.

Palabras clave: Familia; Adopción; Winnicott.

A família considerada como um fenômeno sócio-histórico é múltipla e plural, podendo assumir diversas formas: nuclear, monoparental, homoparental, recomposta, gerada artificialmente, entre outras modalidades (Rios \& Gomes, 2009). A pertença a uma família não corresponde somente à consanguinidade, mas também podem ser compreendidos como membro de uma família aqueles que estabelecem uma relação afetiva ou que coabitam o mesmo ambiente (Alves \& Hueb, 2017; Engels, 1984).

Por esse ângulo, há de se convir que as formações familiares verificadas na sociedade atual sofreram diversas modificações ao longo da história da humanidade (Rios \& Gomes, 2009). Haja vista a família do século XXI, em que diversos modos de agrupamento e de arranjos parentais são observados, verificando-se que, muitas vezes, não é a mãe ou o pai que exercem as funções parentais na família, mas sim outras 
pessoas do núcleo familiar, como os avós ou tios. Ademais, essa função pode encontrarse invertida, com os pais assumindo a posição de filhos, necessitando de cuidados, com os filhos sendo os responsáveis. Dessa forma, cada vez mais encontramos pai-avô, filhamãe, entre outras configurações familiares (Vitorello, 2011).

A despeito das várias modificações que as formações familiares vêm sofrendo ao longo dos anos, há de se destacar que a família, ainda hoje, constitui-se em um ambiente relevante devido às funções que desempenha na vida de seus membros e pelo valor simbólico que a sociedade lhe atribui. Possui um papel fundamental no desenvolvimento dos sujeitos a partir das relações estabelecidas em seu âmbito, das necessidades de cuidados básicos - imprescindíveis para a sobrevivência dos membros - que devem ser por ela atendidas, e do processo de socialização com pessoas externas (Prazeres, 2020; Rossato \& Ferreira, 2017), haja vista que a família é o primeiro núcleo de socialização na vida de um indivíduo.

Nesse sentido, ressalta-se a importância de toda pessoa poder crescer e se desenvolver em uma família; entretanto, sabe-se que há muitas crianças que passam parte de suas vidas em instituições de acolhimento, aguardando a reinserção no agrupamento de origem ou, ainda, aguardando a colocação em uma nova família (Sampaio et al., 2018). A adoção surge como uma oportunidade de crianças que foram retiradas de suas famílias de origem poderem crescer em um novo agrupamento de pessoas que lhes ofereça conforto, afeto e amor (Alves et al., 2017; Pereira \& Azambuja, 2015).

Crianças e adolescentes podem ser retirados, pelo judiciário, do convívio de suas famílias de origem por sofrerem negligência, abusos ou maus-tratos (Maciel et al., 2017), os quais são decorrentes de diversos fatores, como a maternidade precoce, o alcoolismo, a monoparentalidade, entre outros (Silva, 2012). Em geral, tais aspectos podem levar à violação dos direitos da criança/adolescente e, nesses casos, o Estatuto da Criança e do Adolescente - ECA (Brasil, 1990) prevê o acolhimento institucional, sendo que as possibilidades de reintegração da criança na família de origem devem ser esgotadas antes da colocação em família substituta (Alves \& Hueb, 2017).

Porém, há de se destacar que a adoção, por um longo período, foi marginalizada e o filho por tal modalidade de filiação não era visto da mesma forma que um filho consanguíneo, mas sim como um "forasteiro". Hoje essa forma de pertencimento a uma família vem ganhando espaço na sociedade contemporânea (Schettini et al., 2006), sendo considerada como uma dentre as muitas formas de filiação.

É importante frisar que em qualquer forma de filiação é necessária a adoção mútua entre pais e filhos, aquela em que se vigora o afeto e o cuidado (Gondim et al., 2008). Dessa maneira, a adoção pode ser definida como o estabelecimento de vínculos parentais entre pessoas que constroem relações de afeto - sem possuir ligações genéticas - por meio de uma construção paterno-filial e da compreensão das vicissitudes inatas a esse processo (Alves \& Hueb, 2017).

Há de se ressaltar que as pessoas recorrem à adoção por diversos motivos (Schettini et al., 2006), sendo que a infertilidade é apontada como a motivação mais recorrente (Levinzon, 2006; Schettini Filho, 1998). Contudo, novas configurações familiares também buscam, cada vez mais, a filiação por adoção: solteiros, viúvos, casais não estéreis, casais que já possuem filhos e casais do mesmo sexo. Na maioria das vezes, a adoção tem a dupla finalidade de permitir à criança encontrar uma nova família e um ambiente que satisfaça suas necessidades para desenvolver-se, além de permitir o exercício da parentalidade aos pais (Schettini et al., 2006). 
O ambiente proporcionado a uma criança desde os primórdios de sua vida tem importância fundamental para o seu amadurecimento emocional. Winnicott (1988/1990) frisa na teoria do amadurecimento emocional de um indivíduo que cada ser humano nasce com um potencial inato para amadurecer, contudo este dependerá de um ambiente facilitador para acontecer. Portanto, amadurecer significa alcançar o desenvolvimento do que é potencialmente intrínseco - e para tal, é fundamental, no início da vida, um ambiente que consiga oferecer as condições necessárias. Destaca-se que este ambiente se refere a alguém que possa identificar-se com o bebê e oferecer os cuidados necessários a ele; sendo que, na maioria das vezes, essa pessoa é a mãe da criança, podendo ser qualquer outra que seja capaz de se identificar e satisfazer as necessidades do infante.

Todavia, é importante ressaltar que o prolongamento entre as vivências da separação da família de origem e o amparo da família por adoção podem gerar marcas no desenvolvimento da personalidade, além de desencadear sentimento de desamparo na criança (Hueb, 2016; Levinzon, 2008). Nesse sentido, na década de 1950, Winnicott (1953/2008) já frisava a importância de a criança ser colocada o quanto antes em uma nova família que pudesse lhe oferecer as condições necessárias para seu desenvolvimento.

Contudo, na contemporaneidade, com abertura da sociedade para as novas concepções de família, desmitifica-se cada vez mais a adoção. E apesar da maioria dos pretendentes ainda desejar adotar crianças menores, a adoção de crianças maiores acima de dois anos de idade - também ganha espaço, vencendo preconceitos, visto que a função da família, que é de proteção e socialização, independe da idade da criança ou da forma como essa família é composta. Nesse contexto de novas configurações familiares urge desvincular a adoção da ideia de se adotar somente crianças menores, e a Lei 12.010 (Brasil, 2009) revela essa necessidade de mudança no perfil das crianças adotadas no Brasil (Machado et al., 2015). Dessa forma, independentemente da idade da criança, faz-se relevante destacar que toda despedida pode ser um novo encontro (Peiter, 2011), o que explicita que o afastamento da família de origem pode levar à união com uma nova família que acolha e ofereça cuidados e afetos à criança.

Sabendo que o significado de representação familiar se refere à visão/ideia que a criança tem de família e que vai estar ligado aos moldes experienciados por ela, mas também às influências dos constructos sociais e da mídia (Lauz \& Borges, 2013), este estudo objetivou verificar qual a representação de família para uma criança adotada depois dos dois anos de idade, a partir do olhar da própria criança, assim como avaliar seu amadurecimento emocional. Justifica-se a realização desse estudo, uma vez que ele permitiu ao participante ser sujeito de direito capaz de falar e ser ouvido sobre sua própria história, fato ressaltado por pesquisadores (Azevedo \& Sani, 2017; RossettiFerreira et al., 2011) que sinalizam a importância da participação ativa das crianças em pesquisas. 


\section{MÉTODo}

\section{TIPO DE ESTUDO}

Trata-se de um estudo de caso intrínseco, de caráter descritivo, exploratório e de corte transversal. Tal método busca melhor compreensão de um caso particular pelo interesse despertado por ele; desse modo, o caso não é estudado porque representa outros, mas sim porque, em todas as suas particularidades, possui interesse em si mesmo (Stake, 2000). Esse estudo foi aprovado pelo Comitê de Ética em Pesquisa da instituição de origem dos autores sob o parecer número 1.786.494. Ancorado na teoria psicanalítica winnicottiana, utilizou da investigação clínica qualitativa pautada pela adoção de procedimentos projetivos.

\section{PARTICIPANTES}

Participou do estudo uma mãe e seu filho, um menino de nove anos, adotado há três anos. Os critérios de inclusão para a criança foram: (a) ser adotado legalmente; (b) possuir tempo mínimo de um ano de convivência com a família por adoção; (c) possuir idade mínima de cinco anos e máxima de 11 anos e 11 meses; (d) a mãe consentir com a participação do menor na pesquisa por meio da assinatura do Termo de Consentimento Livre e Esclarecido e a criança assentir em participar do estudo. Os critérios de exclusão elencados foram: (a) processo de adoção legal não ter sido concluído e a (b) criança não possuir conhecimento de ter sido adotada.

Já os critérios de inclusão elencados para a mãe foram: (a) mãe e filho residirem no mesmo domicílio; (b) criança ter sido adotada legalmente; (c) mãe ter consentido em participar da pesquisa por meio da assinatura do Termo de Consentimento Livre e Esclarecido. Frisa-se que não houve restrições em relação a aspectos socioeconômicos, atuação profissional e grau de instrução da mãe.

\section{MATERIAL}

Primeiramente, foi realizada uma entrevista semiestruturada com a mãe, visando coletar dados a respeito da experiência da adoção e da convivência familiar, além de conhecer a história de vida da criança. Com o menino foi realizada primeiramente uma Sessão Lúdica, em que foram utilizados brinquedos estruturados, como bonecos da família lúdica, animais domésticos e selvagens, artigos de cozinha, automóveis, e materiais não estruturados, como folhas em branco, lápis de cor, massinha para modelar e tinta guache. Durante esse procedimento não foram realizadas anotações, a fim de não interferir na espontaneidade da criança e do seu brincar. O registro da Sessão Lúdica foi feito retrospectivamente pela pesquisadora. Optou-se pela realização da Sessão Lúdica visto que, de acordo com Klein (1932/1997), o brincar é um meio de expressão e por meio dele a criança pode falar de suas fantasias e desejos.

Na segunda sessão com a criança foi realizada a aplicação do Procedimento de Desenhos de Família com Estórias (DF-E). Tendo como base a importância da família no desenvolvimento de uma pessoa, o DF-E aborda conflitos e dificuldades emocionais que estão relacionados à dinâmica familiar. Esse procedimento é composto por quatro unidades de produção: (1) uma família qualquer, (2) uma família que o examinando gostaria de ter, (3) uma família em que alguém não está bem e (4) a família do 
examinando. Em cada unidade de produção o participante realiza um desenho, conta uma história associada ao desenho, depois é realizado um inquérito em que o pesquisador esclarece dúvidas sobre o que foi feito e, por fim, o participante dá um título ao que produziu (Trinca, 1997). Por último, foi realizada uma terceira sessão com a criança para maior detalhamento do material coletado e intervenções necessárias.

\section{PROCEDIMENTO}

A mãe participante foi contatada a partir da indicação do Grupo de Apoio à Adoção da cidade onde a pesquisa foi realizada. Após a indicação, a pesquisadora entrou em contato com a participante por telefone e informou sobre o trabalho a ser desenvolvido. Devido ao seu interesse em participar, foi agendado um encontro em uma sala reservada no Serviço Escola de Psicologia da universidade à qual os autores do estudo pertencem. Lá foram apresentados e assinados os Termos de Consentimento e de Assentimento Livre e Esclarecidos, demonstrando, assim, a concordância da participante com os termos do estudo. Logo após, foi realizada uma entrevista semiestruturada, a qual foi audiogravada perante sua anuência e, por fim, foram agendados os três encontros seguintes com a criança (Sessão Lúdica, aplicação do DF-E e investigações e realização de intervenções). Todos os procedimentos foram realizados face a face, em data e horário acordados previamente com a mãe da criança.

Os encontros com os participantes foram realizados em salas reservadas e livres de interferências externas, visando garantir sigilo e conforto. Após a realização da entrevista semiestruturada com a mãe, esta foi transcrita integralmente para posterior análise e interpretação dos dados. As anotações da Sessão Lúdica com a criança foram realizadas $\operatorname{logo}$ ao término desta, retomando e narrando os acontecimentos. Na terceira sessão foram realizadas intervenções a fim de possibilitar que a criança pudesse reconhecer suas produções como sendo genuinamente suas e que essas lhe fizessem sentido, sendo possível, assim, realizar uma devolutiva à criança.

Os dados obtidos na Sessão Lúdica e no DF-E foram analisados e interpretados segundo método da livre inspeção do material, a partir do processo compreensivo, sustentados no referencial psicanalítico winnicottiano. $\mathrm{O}$ processo compreensivo constitui-se em uma coleção de situações que incluem "encontrar um sentido para o conjunto das informações disponíveis, tomar aquilo que é relevante e significativo na personalidade, entrar empaticamente em contato emocional e, também, conhecer os motivos profundos da vida emocional de alguém" (Trinca, 1984, p. 15). Recorreu-se à livre inspeção do material, utilizando-se do julgamento clínico e da experiência do psicólogo (Trinca, 1984; Trinca \& Becker, 1984).

Já os dados da entrevista com a mãe foram usados como instrumento auxiliar, ajudando a compreender a história de vida e a adoção da criança. Estes dados também foram interpretados segundo o método da livre inspeção (Tardivo, 1997; Trinca, 1984). As intervenções, realizadas pela pesquisadora no último encontro com a criança, levaram em conta o material emergente durante as sessões anteriores. Importante destacar também que em cada encontro entre pesquisadora e participantes - mãe e criança - consideraram-se os aspectos transferenciais e contratransferenciais da dupla, abordados na sessão "resultados e discussão", a fim de construir o estudo de caso. Destaca-se, ainda, que cada etapa do processo foi supervisionada pela orientadora e pesquisadora deste estudo. 


\section{ReSUltados E DiscuSsão}

Davi, nome fictício da criança participante desse estudo, atualmente tem nove anos e foi adotado pela família substituta aos quatro anos e sete meses. Foi retirado de sua família de origem quando tinha um ano de idade, pois a mãe era usuária de drogas, tendo feito uso das mesmas durante toda a gravidez e amamentação do bebê. Soube-se que Davi tem um irmão consangüíneo por parte de mãe já adulto, e que por duas vezes tentou obter sua guarda, porém, por questões outras, não conseguiu seu intento e devolveu-o à instituição de acolhimento.

Gomes (2006) evidencia que as crianças que mudam de família precisam lidar com dificuldades próprias dessa mudança, assim como a de terem permanecido em instituições, sendo que as instituições de acolhimento não possuem condições de se dedicarem a todas e quaisquer demandas das crianças. Consoante a isso, Winnicott (1953/2008) destaca que é importante que a criança seja colocada o quanto antes em uma nova família, contudo, nem sempre isso é possível, sendo que muitas crianças podem passar um longo tempo em instituições de acolhimento (Alves \& Hueb, 2017; Hueb, 2016).

A família substituta de Davi é composta pela mãe Sofia, por Davi Pai e pelo irmão de 13 anos, Davi Filho (os três possuem o mesmo prenome), que é filho consanguíneo do casal - aqui se destaca o fato instigante dos prenomes iguais. A família se constitui enquanto elemento estruturador da vida de uma criança pelo cuidado e fornecimento de um ambiente que lhe proporcione as condições necessárias para seu amadurecimento físico e emocional (Winnicott, 1986/1999), inclusive de sua individualidade.

A partir dessas condições do ambiente, o amadurecimento vai ocorrendo e a criança progredindo por estágios e se construindo em um ambiente confiável e estimulador, evoluindo da dependência absoluta à dependência relativa e, posteriormente, à independência relativa, adquirindo a identidade unitária (Gomes, 2006). Contudo, no caso de Davi, em que os três homens da família possuem o mesmo prenome, isso pode afetar o processo de individuação, podendo a individualidade não ter espaço para se sobressair dentro da família, sendo que os prenomes iguais podem gerar confusão no reconhecimento, podendo afetar, assim, o amadurecimento emocional.

Sofia, que participou sozinha da entrevista, destacou que não percebe diferença entre os dois filhos, esclarecendo que entende que somente a forma de gestação é diferente, mas o amor maternal é o mesmo. Ademais, realçou que sempre teve o desejo de ter dois filhos, para dividir a responsabilidade que lhes seriam imputadas quando os pais ficassem mais velhos e necessitassem de cuidados. Frisou que, além de ter se casado com mais idade, posteriormente veio a sofrer de uma grave doença, o que levou os médicos a desaconselharam a engravidar novamente, fato que a fez optar pela maternidade adotiva. Entretanto, esclareceu que sempre pensou nessa possibilidade, uma vez que dois irmãos de seu esposo são inférteis, o que a fez supor que o marido também o poderia ser.

Relatou que ela e o marido sempre desejaram adotar um menino mais velho para que pudesse fazer companhia para o primeiro filho. Importante, aqui, destacar a motivação dos pais para a inclusão de Davi na família, motivação relacionada ao irmão, o que levanta a reflexão sobre qual a função que a criança assume dentro da família. Já 
de início presume-se que seria uma tarefa bastante pesada, aquela de ser esperado para vir a ser companhia para um irmão, e não de fato nascer no desejo dos pais.

Como já citado, a adoção vem tomando diferentes formas nas famílias atuais, uma vez que não é mais somente o casal infértil que a realiza, mas também casais que já possuem filhos (Schettini et al., 2006), sendo que as motivações para a adoção são variadas, porém Ebrahim (2001) destaca que pessoas que realizam adoção de crianças maiores apresentam-se como mais maduras e altruístas. Nesse sentido, Gondim et al. (2008) relatam que dentre as motivações para realizar a adoção de crianças evidencia-se alguns postulantes: a necessidade de preencher uma solidão, de dar companhia a um filho único, de preencher o lugar de um filho falecido, entre outras. Todavia, apesar de ser necessário pensar e trabalhar o papel que a criança desempenha na família perante a expectativa que lhe é imputada, não há consenso que a motivação para adoção esteja correlacionada à qualidade da relação estabelecida entre pais e filhos (Weber, 1999; Reppold \& Hutz, 2002), haja vista que a avaliação de um único aspecto frente à adoção é insuficiente diante das variáveis envolvidas na vida dos membros da família (Gondim et al., 2008).

Além disso, Sofia ressaltou que lida muito bem com a adoção e é muito aberta para conversar com o filho sobre o assunto e sobre sua família de origem, diferentemente de seu marido: "[...]Ele fala mais comigo, acho que ele tem mais receio do Davi Pai não aceitar, como ele não aceita mesmo, assim de... vida passada é passada”. Essa colocação remete ao quanto algumas famílias adotivas têm dificuldade de falar sobre a ambivalência de sentimentos ou de sentimentos destrutivos que podem estar presentes na adoção, tendo a ideia que abordar esses sentimentos é como se invalidasse o que há de bom na nova família, na adoção; "vida passada, é passada" remete à ideia de que a história pregressa é ruim, e que depois de concretizada a adoção, somente o lado bom prevalecerá. Porém, a criança necessita de uma pessoa confiável que esteja ao seu lado na busca da verdade e entenda sua necessidade em experienciar a emoção apropriada à realidade, ou seja, a criança deve poder sentir tristeza, raiva, exasperação ou desgosto, de acordo com as circunstâncias que vivencia na adoção e na vida, somente assim ela poderá alcançar o amor de seus pais/responsáveis, atingindo sua própria capacidade de amar (Winnicott, 1955/2008).

Um dos aspectos que pode estar vinculado ao desejo de apagar a história pregressa da criança é a negação da adoção como uma forma diferente de parentalidade, sendo que muitas vezes a adoção se apóia na negação da diferença entre a parentalidade consanguínea e adotiva (Costa \& Campos, 2003). Hartman (1994), inclusive, destaca que a família consanguínea é a negação dessa diferença e, por isso, a ideia de que essa conexão deve ser rompida é veiculada por alguns pais amedrontados, ou seja, a família de origem não deve ser falada/lembrada. Porém, esse desconhecimento e a não abertura para falar sobre sua história pode desencadear dificuldades para a criança - sentimentos de vazio, problemas de comunicação e relacionamentos - e também para a família por adoção (Costa \& Campos, 2003).

É essencial que os pais/mães, ao cuidar de uma criança que vivenciou o processo de adoção e sofreu de-privação - ou seja, que recebeu cuidados no inicio da vida, mas que estes foram retirados de forma abrupta e não puderam ser retidos na memória do indivíduo, o que faz com que ele passe a buscar esse cuidado no ambiente -, adapte-se às necessidades dela ao longo de seu amadurecimento, podendo, assim, vir a "tratar" essa criança. A adoção deve lhe fornecer um ambiente confiável, que lhe propicie cuidados especiais, que não ignore sua história e traumas sofridos anteriormente, logo 
os pais/mães precisam saber que essa criança sofreu de-privação e que necessitará de maiores cuidados (Gomes, 2006).

Nesse sentido, Winnicott (1953/2008) ressalta que a mãe por adoção, ao tornarse mãe, torna-se terapeuta de uma criança que sofreu privação ou de-privação, sendo que os pais por adoção terão que sobreviver aos ataques de raiva da criança, e essa tolerância fundamental, pois a criança necessita experimentar o ódio externo a eles; assim, a mãe, ao trazer para a criança sua história de vida e também o ódio, lhe proporcionará um espaço terapêutico, espaço esse que será sua própria casa.

No caso de Davi é possível perceber que a mãe fornece esse espaço ao filho, diferentemente do pai, sendo que Sofia relatou que percebe que os dois filhos se sentem mais próximos a ela. Esse fato é reiterado ao longo da Sessão Lúdica com Davi, na qual apresentou situações vivenciadas somente relacionadas à mãe ou ao irmão, como durante a brincadeira de cozinhar, em que relatou gostar de comer tudo o que a mãe cozinha. Também narrou que dorme na sala com a mãe e o irmão, e, quando indagado sobre seu pai, respondeu que às vezes este dorme fora de casa ou em outro quarto. Além disso, há de se ressaltar que Davi pediu para sair da sala de atendimento por duas vezes para ir ao encontro da mãe na sala de entrada. Primeiramente, justificou que era por estar com saudades, na segunda vez disse que era para mostrar-lhe sua pintura. O pai também se encontrava na sala de espera e Davi não se dirigiu a ele.

Essa atitude de Davi assinala a importância da constância do objeto, de verificar que a mãe se mantém presente, que não o abandonou, visto que já foi abandonado tanto pela mãe quanto pelo irmão consanguíneo. Destaca-se que, de um modo geral, a criança tem capacidade limitada para manter viva a imagem/ideia de uma pessoa amada quando inexiste oportunidade de ver ou falar com essa pessoa, e que quando esse tempo de separação é longo demais para a criança, essa não consegue mais sentir que sua mãe seja real ou passa a ter a ideia de que algo ruim irá lhe acontecer (Winnicott, 1987/1999). Na criança que vivenciou o processo adotivo, esta necessidade de manter a imagem viva da mãe é ainda mais impetuosa, visto a história de abandono que já vivenciou.

Na busca por um suporte emocional, observa-se que Davi procura estabelecer a relação com a mãe a partir do alimento concreto, como expressado em uma brincadeira de "fazer comidinha" na Sessão Lúdica e no relato de que "gosta de comer tudo que a mãe faz", fato confirmado na entrevista com Sofia, na qual antecipa-nos que Davi gosta de comer tudo que ela também aprecia. Ao receber o alimento, cumprindo a função nutritiva e sanando a fome, a criança em geral tem uma sensação agradável, o que leva à necessidade da repetição não apenas pelas questões biológicas, mas também pelo prazer concomitantemente proporcionado (Dilger, 2015).

Nesse sentido, o alimento (objeto objetivamente percebido) é usado como objeto transicional e transformado em simbólico (objeto subjetivamente percebido), possibilitando, assim, a continuidade do amadurecimento emocional (Winnicott, 1951/2000). Diferentemente da genitora que amamentava Davi quando usuária de crack, sua atual mãe o alimenta com "comida gostosa", o que remete a relevância da amamentação, que é o primeiro contato da criança com o outro, ou seja, a importância do primeiro contato com o mundo, e se este contato não for suficientemente bom, pode trazer prejuízos ao desenvolvimento da criança.

Em um dos momentos na Sessão Lúdica, Davi falou que sabia que estava ali para contar sua história e relatou que nasceu em outra cidade, que "brincava com o avô, mas depois foi morar na Casa Lar, e que lá batiam nele e que depois veio morar com 
sua mãe e... Fim!". Quando indagado sobre como era na instituição de acolhimento, nomeada por ele de "Casa Lar", respondeu "ruim" e quando questionado sobre morar com sua família atual disse que "é bom", dando respostas monossilábicas ou evasivas às perguntas, retornando em seguida à brincadeira de "fazer comida" que estava realizando.

Pode-se pensar que falar sobre todo o processo da adoção, sobre sua família de origem e sua família substituta, é ainda um assunto dolorido, ansiogênico e difícil de ser expresso, colocado em palavras, para ele. Essa percepção foi reiterada na sessão de aplicação do DF-E, na qual demonstrou resistência ao realizar os desenhos e contar as histórias e, ademais, na terceira sessão, em que foi proposto conversar sobre suas produções, demonstrou não conseguir falar muito sobre o assunto relacionado às famílias, querendo terminar logo para poder realizar outra atividade.

Na quarta Unidade de Produção (Figura 1), em que lhe foi dado a consígna Desenhe sua família, contou que estava andando pela floresta, seus pais o encontraram e pediram para ficar com ele. Ao realizar-se o inquérito, buscando investigar mais sobre o desenho e a história, Davi demonstrou irritação, ameaçou raivosamente quebrar o lápis de cor ao meio, o que de fato cumpriu, porém, logo em seguida, sentiu-se culpado e buscou uma reparação perguntando se daria para consertar o lápis.

Winnicott (1987/1999) destaca que a ambivalência entre amor e ódio é essencial para o aprendizado da reparação e também para o desenvolvimento dos sentimentos, visto que a partir da agressão e do ódio a criança pode sentir culpa e reparar; o autor coloca "sem uma pessoa a quem possa amar e odiar, a criança não pode chegar, a saber, amar e odiar a mesma pessoa e, assim, não pode descobrir seu sentimento de culpa nem o seu desejo de restaurar e recuperar" (p. 63). Davi nomeou sua produção de Família Ratoui - frisa-se que os títulos apresentados nas figuras a seguir foram dados pela própria criança para as unidades de produção no DF-E.

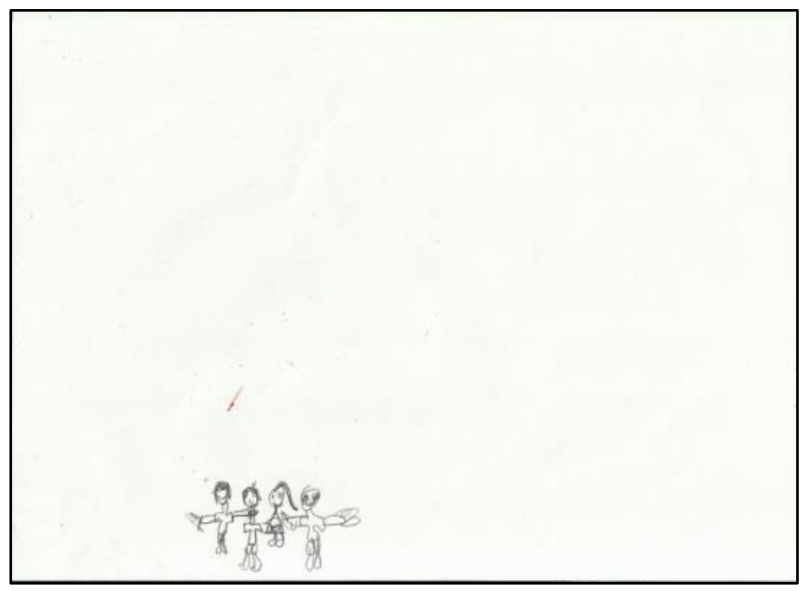

Figura 1

A família Ratoui 


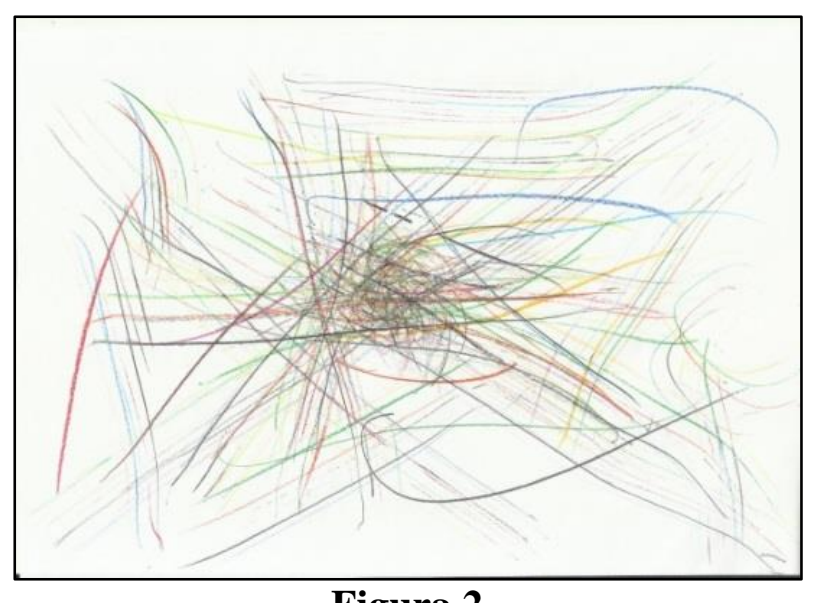

Figura 2

A família de poderes

$\mathrm{Na}$ segunda Unidade de Produção (Figura 2), com a consígna "A família que você gostaria de ter", Davi relatou "Isso é uma família e não tem nenhuma história. Ela é com poderes. Você viu o 'Lar das crianças peculiares'? São famílias peculiares". Enquanto realizava o desenho ele disse que queria ter uma "família borrada". Essa colocação foi retomada na sessão seguinte e Davi explicou que uma família borrada era aquela que não tinha direito de cuidar da criança e citou como exemplo sua genitora, dizendo que ela não pôde ficar com ele porque não tinha dinheiro e condições de criá-lo, ou seja, a própria criança faz referência a um cenário de desigualdade de condições.

Foi possível colocar para a criança que uma "família borrada" parecia ser uma família em que se quer apagar a história, e ao indagar sobre qual seria a história a ser apagada, a criança pôde expressar, então, sobre o desejo de apagar que a família não pôde criar o filho. Ao ser questionado sobre como apagaria essa história, contou que iria mandá-los trabalhar para ter dinheiro e poder ficar com ele, e que, então, a história seria toda diferente, pois sua família de origem ficaria com ele e não teria história, relatando que "ia ser uma família de verdade". Davi demonstrou não ter elaborado ainda sua separação da família de origem, sentindo também que sua família substituta não é uma família de verdade, o que de fato parece vir ao encontro da realidade, visto que seu pai não se envolve muito, é um pai que está presente fisicamente, mas não se mostra presente afetiva e subjetivamente, não assumindo a função de pai, como foi possível perceber na Sessão Lúdica com Davi.

Faz-se importante ressaltar que a adoção de Davi se trata de uma adoção de criança maior, ou seja, adoção de crianças acima de dois anos, como Silva (2010) destaca, esse tipo de adoção requer maiores cuidados visto que essas crianças, além de terem sido abandonadas pela família de origem, viveram sucessivas frustrações e perdas. Contudo, a adaptação da criança à nova família dependerá de suas características pessoais e de como vivencia as perdas; nesse sentido, destaca-se a extrema importância da família por adoção e de seu preparo para lidar com a história de vida da criança.

Sobre as motivações que levaram à adoção, destacar destaca-se que a adoção de Davi ocorreu após a identificação de uma falta: Sofia não podia engravidar novamente. Dessa forma, apesar da adoção vir ganhando cada vez mais espaço e sendo realizada por diferentes motivos e configurações familiares, como famílias que já possuem filhos 
(Schettini et al., 2006), a realidade deste caso vai ao encontro ao que a literatura aponta: a infertilidade ainda aparece como um dos principais motivos (Levinzon, 2006; Schettini Filho, 1998).

Por fim, é possível observar o quanto a figura paterna, ausente no caso de Davi e que pouco aparece em seus relatos, ainda assim se faz essencial na vida da criança: Davi não o tem presente, mas ressente-se de sua ausência. Já a mãe aparece como a figura de confiança e que oferece o ambiente seguro para seu desenvolvimento. Dessa forma, fica evidente que se deve respeitar a história da criança, ou seja, não se devem apagar as figuras que fizeram parte de sua história pregressa, mas é possível fazer um novo desfecho com esses personagens, criar uma nova história que complemente a antiga, mas que não a negue.

\section{CONSIDERAÇÕES FINAIS}

Este estudo teve como intuito verificar qual a representação de família de uma criança adotada depois dos dois anos de idade a partir do olhar da própria criança, assim como conhecer seu desenvolvimento emocional. Este estudo de caso intrínseco demonstra a importância de se falar sobre a família de origem e de que a criança possa desenvolver a confiança para indagar e conhecer sua história, visto que quando há esse espaço a criança aproxima-se e identifica-se com o cuidador.

Apesar da omissão afetiva do pai, Davi encontra na mãe o ambiente seguro e terapêutico para desenvolver-se, identificando e aproximando-se dela. Esse ambiente seguro e acolhedor do novo lar parece proporcionar as condições necessárias para o processo de amadurecimento. $\mathrm{O}$ que ressalta a importância da necessidade de cuidado da criança que sofreu de-privação no início da vida, haja vista que o abandono sofrido gera consequências, como o fato de Davi se sentir uma criança peculiar, mas essas consequências podem ser acolhidas pela família substituta quando há espaço para isso. Contudo, quando esse espaço para elaborar a história de origem não é ofertado na família substituta, o distanciamento e a falta de segurança no ambiente podem emergir na criança e na família.

O estudo ressalta a necessidade de pais/mães compreenderem que a criança adotiva tem uma história de abandono e sofrimento e que terá necessidades diferentes daquelas que não vivenciaram o processo de adoção, mas que ao encontrar uma nova família que a acolha e esteja disposta a atender suas necessidades, ela poderá desenvolver-se, vivendo uma história com alegrias e contratempos que fazem parte da história de qualquer ser humano. Além disso, ressalta-se que cada família é única e que são diversos os modelos e relações existentes, o que leva à importância de se conhecer cada família em sua singularidade, compreendendo sua dinâmica dentro de suas experiências, indo além de rótulos e generalizações que se fazem impensáveis quando se trata das variadas formas de relacionamento humano.

Por fim, esta pesquisa incentiva a realização de novos estudos na área que possam retomar a temática abordada, realizando estudos com maior quantidade de participantes e que também contem com a participação da figura paterna (frisa-se que o pai de Davi foi convidado a participar da pesquisa, mas mesmo assentindo com a participação não compareceu no dia e horário marcado, sendo que somente a mãe o fez). Ademais, destaca-se a importância de se investigar e dar voz às crianças e legitimar seus pensamentos e opiniões, reconhecendo-as como capazes de pronunciar sobre si mesmas, 
sua vida e suas experiências. Buscou-se estudar um caso particular de adoção e esperase que as colocações e reflexões aqui realizadas posam ajudar crianças e famílias por adoção, além de profissionais que trabalham com essa temática, ajudando a desenvolver ações que visem buscar sempre o melhor para estas crianças que estão à procura de uma família e para os pais/mães que estão à procura da adoção de uma criança.

\section{REFERÊNCIAS}

Alves, J. R., \& Hueb, M. F. D. (2017). Devolução de crianças e adolescente no processo de adoção: Um ensaio teórico. In C. A. Chapadeiro, C. A. Serralha, M. F. D. Hueb (Orgs.), Questões de Família (pp. 15-28). CRV.

Alves, J. R., Hueb, M. F. D., \& Scorsolini-Comin, F. (2017). Desenvolvimento emocional de crianças que vivenciaram o processo adotivo: Revisão integrativa da literatura. Clínicos, $\quad$ Contextos $\quad$ 10(2): http://dx.doi.org/10.4013/ctc.2017.102.11

Azevedo, V., \& Sani, A. I. (2017). "Ser ou não ouvida": Percepções de crianças expostas à violência doméstica. Análise Psicológica, 4(35), 487-497. https://doi.org/10.14417/ap.1325

Brasil. (1990). Lei n. 8.069, de 13 de julho de 1990. Estabelece o Estatuto da Criança e do

Adolescente. Brasília: Presidência da República. Disponível em: http://www.planalto.gov.br/ccivil_03/leis/L8069. htm

Brasil. (2009). Lei n. 12.010, de 3 de agosto de 2009. Dispõe sobre adoção. Diário Oficial da União, Seção 1. Brasília: Autor. Disponível em: http://www.planalto.gov.br/ccivil_03/_Ato2007-2010/2009/Lei/L12010.htm

Costa, L. F., \& Campos, N. M. V. (2003). A avaliação psicossocial no contexto da adoção: Vivências das famílias adotantes. Psicologia: Teoria e Pesquisa, 19(3), 221-230. http://dx.doi.org/10.1590/S0102-37722003000300004.

Dilger, A. P. (2015). Sobre a destrutividade nas relações amorosas: Contribuições psicanalíticas de Freud e Winnicott. [Dissertação de Mestrado], Setor de Ciências Humanas, Universidade Federal do Paraná, Curitiba, PR. https://acervodigital.ufpr.br/handle/1884/40937

Ebrahim, S. G. (2001). Adoção tardia: Altruísmo, maturidade e estabilidade emocional. Psicologia: Reflexão e Crítica, 1(1), 73-80. https://doi.org/10.1590/S010279722001000100006.

Engels, F. (1984). A origem da família, da propriedade privada e do Estado. Editora Bomtempo.

Gomes, K. (2006). A adoção à luz da teoria Winnicottiana. Winnicott E-prints, 1(2), 5168.

http://pepsic.bvsalud.org/scielo.php?script=sci_arttext\&pid=S1679432X2006000200005

Gondim, A. K., Crispim, C. S., Fernandes, F. H. T., Rosendo, J. C., Brito, T. M. C. D., Oliveira, U. B. D., \& Nakano, T. D. C. (2008). Motivações dos pais para a prática da adoção. Boletim de Psicologia, 58(129), 161-170. Disponível em: http://pepsic.bvsalud.org/scielo.php?script=sci_arttext\&pid=S000659432008000200004 
Hartman, A. (1994). Segredos na adoção. In E. Imber-Black (Org.), Os segredos na família e na terapia familiar (pp. 94-112). Artes Médicas.

Hueb, M. F. D. (2016). Acolhimento institucional e adoção: Uma interlocução necessária. Revista da SPAGESP, 17(1), 28-38. Disponível em: http://bases.bireme.br/cgi-

bin/wxislind.exe/iah/online/?IsisScript=iah/iah.xis\&src=google\&base=LILACS\&l ang=p\&nextAction=lnk\&exprSearch=791892\&indexSearch=ID

Klein, M. (1997). Psicanálise da criança. Editora MestreJou. (Original publicado em 1932)

Lauz, G. V. M., \& Borges, J. L. (2013). Concepção de família por parte de crianças em situação de acolhimento institucional e por parte de profissionais. Psicologia: Ciência e Profissão, 33(4), 852-867. https://doi.org/10.1590/S141498932013000400007

Levinzon, G. K. (2006). A adoção clínica psicanalítica: O trabalho com os pais adotivos. Mudanças: Psicologia da Saúde, 14(1), 24-31. Disponível em: https://www.researchgate.net/publication/273303089_A_Adocao_na_Clinica_Psica nalitica_O_Trabalho_com_os_Pais_Adotivos

Levinzon, G. K. (2008). A criança adotiva na clínica psicanalítica. Escuta.

Maciel, R. F. M., Teodoro, M. C., Alves, J. R., Queiroz, L. G., Ribeiro, L. M., Serralha, C. A. (2017). Crianças à espera de adoção ou em medida protetiva: A inclusão escolar. Revista da SPAGESP, 18(1), 63-79. Disponível em: http://pepsic.bvsalud.org/scielo.php?script=sci_arttext\&pid=S167729702017000100006

Machado, L. V., Ferreira, R. R., \& Seron, P. C. (2015). Adoção de crianças maiores: Sobre aspectos legais e construção do vínculo afetivo. Estudos Interdisciplinares em Psicologia, 6(1), 65-81. Disponível em: http://pepsic.bvsalud.org/scielo.php?script=sci_arttext\&pid=S223664072015000100006

Peiter, C. (2011). Adoção: Vínculos e rupturas: Do abrigo à família adotiva. Zagodoni.

Pereira, A. K., \& Azambuja, M. R. F. (2015). História e legislação da adoção no Brasil. In F. Scorsolini-Comin, A. K. Pereira \& M. L. T. Nunes (Orgs.), Adoção: Legislação, cenários e práticas (pp. 17-27). Vetor.

Prazeres, G. A. (2020). A importância da família como expressão dos direitos humanos e as suas intersecções com a Educação e a Escola na Educação Brasileira. Filosofia e Educação, 12(2), 1193-1211. https://doi.org/10.20396/rfe.v12i2.8660968

Reppold, C. T., \& Hutz, C. S. (2002). Adoção: Fatores de risco e proteção à adaptação psicológica. In C. S. Hutz (Org.), Situações de risco e vulnerabilidade na infância e na adolescência: Aspectos teóricos e estratégias de intervenção (pp. 89-130). Casa do Psicólogo.

Rios, M. G., \& Gomes, I. C. (2009). Casamento contemporâneo: Revisão de literatura acerca

da opção por não ter filhos. Estudos de Psicologia, 26(2), 215-225. https://doi.org/10.1590/S0103-166X2009000200009.

Rossato, L., \& Ferreira, C. B. (2017). Apontamentos sobre o grupo familiar nas perspectivas psicanalíticas e sistêmica. In: C. A. Chapadeiro, C. A. Serralha, M. F. D. Hueb (Orgs.), Questões de Família (pp. 15-28). CRV. 
Rossetti-Ferreira, M. C., Serrano, S. A. P., \& Almeida, I. G. (2011). O acolhimento institucional na perspectiva da criança. Hucitec.

Sampaio, D. S., Magalhães, A. S., \& Féres-Carneiro, T. (2018). Pedras no caminho da adoção tardia: Desafios para o vinculo parento-filial na percepção dos pais. Temas em Psicologia, 26(1), 311-324. https://doi.org/10.9788/tp2018.1-12pt

Schettini Filho, L. (1998). Compreendendoos paisadotivos. Recife: Bagaço.

Schettini, S. S. M., Amazonas, M. C. L. A., \& Dias, C. M. S. B. (2006). Famílias adotivas: Identidade e diferença. Psicologia em Estudo, 11(2), 285-293. https://doi.org/10.1590/S1413-73722006000200007

Silva, J. A. (2010). Adoção de crianças maiores: Percepções e vivencias dos adotados. Psicologia em Revista, 16(2), 434-436. Disponível em: http://pepsic.bvsalud.org/scielo.php?script=sci_arttext\&pid=S167711682010000200014

Silva, M. S. A. N. (2012). Construindo vínculos: Escuta psicanalítica para histórias de adoção. Psicologia em Pediatria, 48(9), 376-382. Disponível em: https://pesquisa.bvsalud.org/portal/resource/pt/lil-666292

Stake, R. E. (2000). Case studies. In N. K. Denzin, \& Y. S. Lincoln (Orgs.), Handbook of qualitative research (pp. 435-454). London: Sage.

Tardivo, L. S. P. C. (1997). Análise e Interpretação. In W. Trinca (Org.), Formas de investigação clínica em psicologia (pp. 115-156). Vetor.

Trinca, W. (1984). Diagnóstico psicológico: A prática clínica. São Paulo: EPU.

Trinca, A. M. T., \& Becker, E. (1984). O pensamento clínico e a integração dos dados no diagnóstico psicológico. In: W. Trinca e colaboradores (Orgs.), Diagnóstico psicológico: A prática clínica (pp. 82-94). São Paulo: EPU.

Trinca, W. (1997). Apresentação e Aplicação. In W. Trinca (Org.), Formas de investigação clínica em psicologia: Procedimento de desenhos-estórias: Procedimento de desenhos de família com estórias (pp. 11-34). Vetor.

Vitorello, M. A. (2011). Família contemporânea e as funções parentais: Há nela um ato de amor? Psicologia da Educação, 32(1),7-24. Disponível em: http://pepsic.bvsalud.org/scielo.php?script=sci_arttext\&pid=S141469752011000100002

Weber, L. N. D. (1999). Aspectos psicológicos da adoção. Juruá.

Winnicott, D. W. (1990). Natureza Humana. Imago. (Original publicado em 1988)

Winnicott, D. W. (1999). Tudo começa em casa. Martins Fontes. (Original publicado em 1986)

Winnicott, D. W. (1999). Privação e delinquência. Martin Fontes. (Original publicado em 1987)

Winnicott, D. W. (2000). Objetos transicionais e fenômenos transicionais. In D. W. Winnicott (Org.), Da Pediatria à Psicanálise: obras escolhidas (pp. 316-331). Imago. (Original publicado em 1951)

Winnicott, D. W. (2008). Duas crianças adotadas. In R. Sheperd, J. Johns, \& H. T. Robinson (Orgs.), D. W. Winnicott: Pensando sobre crianças (pp. 115-125). Artmed. (Original publicado em 1953)

Winnicott, D. W. (2008). A adolescência das crianças adotadas. In R. Sheperd, J. Johns, \& H. T. Robinson (Orgs.), D. W. Winnicott: Pensando sobre crianças (pp. 131140). Artmed. (Original publicado em 1955) 
Recebido: $17 / 10 / 2020$

Reformulado: $16 / 04 / 2021$

Aceito: $22 / 04 / 2021$

\section{Sobre as autoras:}

Jéssika Rodrigues Alves é doutoranda em Psicologia pela Faculdade de Filosofia, Ciências e Letras de Ribeirão Preto da Universidade de São Paulo e docente da Universidade de Uberaba.

Martha Franco Diniz Hueb é doutora em Saúde Mental pela Faculdade de Medicina de Ribeirão Preto da Universidade de São Paulo e docente aposentada da Universidade Federal do Triângulo Mineiro.

Correspondência: jessikaralves@yahoo.com.br 